\title{
PATOLOGIAS NARCÍSICAS E DOENÇAS AUTO-IMUNES: ALGUMAS CONSIDERAÇŌES SOBRE O CORPO NA CLÍNICA
}

\author{
Teresa Pinheiro* \\ Júlio Verztman ${ }^{* *}$ \\ Camilo Venturini*** \\ Diane Viana ${ }^{* * * *}$ \\ Lindinaura Canosa ${ }^{* * * * *}$ \\ Selena Caravelli*****
}

\section{Resumo}

O presente artigo visa apresentar os desdobramentos de um dos eixos temáticos fundamentais do projeto de pesquisa intitulado Patologias narcísicas e doenças auto-imunes: estudo comparativo sob a ótica da psicanálise, comparação clínica e metapsicológica entre pacientes melancólicos e portadores de Lúpus Eritematoso Sistêmico (LES), que se realiza

* Psicanalista, Professora do Programa de Pós-graduação em Teoria Psicanalítica - PPGTP/ UFRJ, Pesquisadora do CNPq, Coordenadora da Pesquisa Patologias narcísicas e doenças autoimunes: estudo comparativo sob a ótica da psicanálise.

** Psiquiatra, Psicanalista, Doutor pelo Instituto de Psiquiatria da Universidade do Brasil IPUB/UFRJ, Psiquiatra do IPUB/UFRJ, Coordenador da Pesquisa Patologias narcísicas e doenças auto-imunes: estudo comparativo sob a ótica da psicanálise.

*** Mestrando do Instituto de Medicina Social - IMS da Universidade do Estado do Rio de Janeiro - UERJ.

**** Doutoranda do Programa de Pós-graduação em Teoria Psicanalítica da Universidade Federal do Rio de Janeiro - UFRJ.

***** Mestranda do Programa de Pós-graduação em Teoria Psicanalítica Universidade Federal do Rio de Janeiro - UFRJ.

****** Doutoranda do Programa de Pós-graduação em Teoria Psicanalítica Universidade Federal do Rio de Janeiro - UFRJ. 
a partir de um acordo entre o Instituto de Psicologia, o Instituto de Psiquiatria e o Hospital Universitário Clementino Fraga Filho da UFRJ. Trata-se aqui de pensar a relação que as pacientes atendidas pela pesquisa estabelecem com o próprio corpo. O desenvolvimento teórico-clínico da pesquisa apontou-nos a especificidade com que o corpo se apresenta em ambas as configurações subjetivas. Consideramos esta uma questão fundamental, uma vez que, nesses casos, o estatuto do corpo diverge daquele que costumamos delinear pelo viés da neurose.

Palavras-chave: corpo, psicanálise, pesquisa clínica, doenças auto-imunes, melancolia

\section{ABSTRACT}

NARCISSISTIC PATHOLOGIES AND AUTOIMMUNE DISEASES: SOME ASSUMPTIONS ABOUT THE BODY IN CLINICAL WORK

This article aims to present the developments of one of the fundamental thematic axes of the research project called, Narcissistic Pathologies and Autoimmune Diseases: a comparative study from the psychoanalytical viewpoint, amongst Melancholic Patients and Sufferers of Systemic Lupus Erythematosus (SLE), which is being carried out as a result of an agreement involving the Psychology Institute (IP/UFRJ), the Psychiatry Institute (IPUB/UFRJ) and the Clementino Fraga Filho University Hospital (HUCFF/UFRJ). Here we reflect on the relationship that the patients treated establish with their own bodies. The theoretical and clinical development of the research has directed us towards the specific way that the body is presented in both subjective configurations. We consider this to be a fundamental issue since, in these cases, the body configuration is different from that which we usually observe as a result of this neurosis.

Keywords: body, psychoanalysis, clinical survey, autoimmune illnesses, melancholy

Este trabalho é um desdobramento da nossa participação na pesquisa clínico-teórica Patologias narcísicas e doenças auto-imunes: estudo comparativo sob a ótica da psicanálise que é realizada em função do acordo entre o Programa de Pósgraduação em Teoria Psicanalítica da UFRJ, o Instituto de Psiquiatria da Universidade do Brasil (IPUB), do Rio de Janeiro, e o Hospital Universitário Clementino Fraga Filho (HUCFF) - UFRJ, do Rio de Janeiro ${ }^{1}$. Esta pesquisa decorre das interrogações que temos feito nos últimos anos sobre os impasses da clínica frente às chamadas novas formas de sofrimento psíquico. Estas últimas constituem um desafio, visto contradizerem certos pressupostos básicos sobre os quais o aparelho psíquico freudiano foi assentado. Dados preliminares levaram-nos à hipótese de que as pacientes lúpicas apresentavam importantes características em comum com o modelo narcísico que vínhamos pesquisando anteriormente, cujo principal paradigma seria a melancolia. Nas pacientes portadoras de Lúpus eritematoso sistê- 
mico (LES) ${ }^{2}$, entretanto, o corpo parecia expressar algo que os sujeitos melancólicos não seriam mais capazes de fazer. Características como a vivência da temporalidade achatada, a fixação da identidade em uma imagem sem perspectiva, a pretensão à univocidade da linguagem, entre outras, eram fatores marcantes encontrados nesses dois grupos de sujeitos - o que nos incitou à tarefa de investigação por considerarmos que poderiam nos fornecer importantes elementos para uma reflexão acerca da clínica contemporânea ${ }^{3}$. Este artigo faz parte de um conjunto de quatro artigos (além deste, um sobre metodologia de pesquisa em clínica psicanalítica, outro sobre a relação dos pacientes com o tempo e um terceiro sobre a transferência) que pretendem retratar o trabalho da pesquisa até a presente data.

Neste artigo especificamente, o nosso objetivo é trabalhar a relação que essas pacientes atendidas pela pesquisa estabelecem com o próprio corpo. Trata-se de uma questão fundamental para pensar estes casos, visto que a dimensão corporal não se desdobra como nas neuroses em geral. Nessas patologias, o que se apresenta como característico é o fato de que a auto-imagem corporal de que dispóem tais sujeitos parece não permanecer no tempo, como se não tivesse consistência, vindo a falhar num determinado momento. Por isso, para essas pacientes, a relação com o corpo terá um estatuto particular, o que faz com que a busca de uma imagem corporal seja muitas vezes urgente, provocando muita angústia.

Antes de prosseguir, para evitar mal-entendidos, gostaríamos de esclarecer que não temos qualquer intenção de apresentar uma perspectiva sobre o corpo fundada numa relação de causalidade com o psiquismo, como desejam algumas investigações inscritas no campo da psicossomática. O foco da pesquisa não é verificar se o psíquico é causa de - ou determina - efeitos no corpo, ou vice-versa. No nosso estudo comparativo entre pacientes melancólicas e aquelas portadoras de Lúpus Eritematoso Sistêmico (LES), pensamos o corpo e o psiquismo como instâncias absolutamente integradas, indissociáveis do ponto de vista da dinâmica subjetiva das nossas pacientes, sem uma hipótese causal reducionista. No intuito de enriquecer o estofo clínico-teórico dessa ordenação subjetiva que vem se apresentando com tanta insistência na clínica contemporânea, proporemos algumas reflexões acerca do papel do corpo para essas pacientes, que lugar esse corpo ocupa, quais são as suas especificidades.

\section{NOTAS SOBRE A IMAGEM CORPORAL}

Uma questão fundamental para se pensar a relação deste tipo de clientela com a corporeidade é a da imagem corporal, que se apresentará recheada de algumas peculiaridades irredutíveis aos modelos da neurose, psicose e perversão, sobre 
os quais foi assentado o aparelho psíquico freudiano. Nos casos atendidos pela pesquisa não constatamos um estado de desintegração corporal, como se observa em casos de psicose. Não se trata disso. Há nessas pacientes uma idéia mínima de unidade corporal consolidada. Todavia, essa unificação é frágil, provisória e vacilante. Nossa hipótese é a de que essas pacientes convivem com um certo evanescimento da própria imagem corporal, marcada por um equilíbrio precário, prestes a desmontar, estado que pode ser gerador de muita angústia.

Ferenczi - cuja obra concedeu bastante destaque à questão da corporeidade, pensada freqüentemente em relação aos ditos casos difíceis -, no seu artigo Reflexôes psicanaliticas sobre os tiques (1921/1988), oferece instrumentos conceituais que podem nos ajudar a refletir sobre o estatuto singular dessa imagem corporal hesitante que constatamos na nossa clínica. Nesse artigo, o autor vai pensar os tiques de forma análoga à teoria da angústia: um impulso interno que descarrega sem fazer qualquer trilhamento, isto é, sem ter tido a possibilidade de ganhar a palavra. Desta maneira, o tique seria uma descarga motora materializada no corpo, algo que não foi capaz de estabelecer uma ligação psíquica ou uma produção de sentido: "Consideramos que os tiques, pelo fato mesmo do forte narcisismo ou de uma fixação neste estádio dos seus portadores, têm uma tendência para a descarga, mas uma capacidade reduzida de ligação psíquica" (Ferenczi, 1921/1988: 165). Numa passagem do texto, ao analisar o trabalho de dois médicos que haviam tido sucesso no tratamento dos tiques por um método que combinava exercícios corporais desempenhados na frente de um espelho, Ferenczi conclui que o sucesso do tratamento devia-se muito menos aos exercícios combinados do que ao fato de aqueles pacientes estarem pela primeira vez se vendo executar os tiques diante de um espelho. Foi, portanto, necessária a concretude material de um espelho para que aqueles sujeitos pudessem ter a noção da imagem corporal de um gesto que até então não era por eles percebido. Este ponto nos parece fundamental, pois vai ao encontro da descrição de uma subjetividade que ultrapassa o modelo pensado a partir da organização histérica e que se assemelha, em muitos aspectos, com o que temos observado com freqüência na clínica contemporânea, em particular, nas pacientes da pesquisa. Ferenczi procurava assinalar com essa passagem a existência de um determinado tipo de ordenaçãao subjetiva não calcada na função interpretativa e que seria uma função decorrente de um instrumental fantasmático presente eminentemente na neurose, sobretudo na histeria. Aqueles pacientes não pareciam ser capazes de se colocar no lugar do outro, para imaginar o que este pensa, sente e deseja, premissa fundamental para a antecipação da autoimagem corporal. Era necessário que se lhes mostrasse essa imagem projetada num espelho, como se a imagem do próprio corpo carecesse de um eco interno 
que lhes assegurasse uma consistência. O que Ferenczi nos aponta neste texto é que para esses pacientes é preciso ter a visão de fato da própria expressão facial para se dar conta do que ela produz, como se não fosse possível, apenas por meio do recurso do estofo fantasmático interpretativo, representar-se no lugar do outro que assiste ao tique e pressupor a imagem e a expressão facial que ele observa. Portanto, a auto-imagem corporal, nesses casos, é concebida como uma unidade sem recheio, ou como uma imagem inconsistente e insegura.

Com relação às nossas pacientes, constatamos que, se, por um lado, possuem um senso de totalidade do próprio corpo, por outro, não é nessa totalidade que elas se reconhecem. Embora o corpo seja reconhecido como próprio e distinto, pouca relação de intimidade ou privacidade é estabelecida com ele. O corpo mais parece um invólucro exterior, uma casca. Isso se expressa numa organização subjetiva dotada de transparência, ou numa ausência de segredo, que faz com que o sujeito - ainda que não tenha uma atitude suspicaz para com o analista - atribua a este um saber sobre particularidades não faladas, ou objetos não mostrados. Pergunta de uma paciente à sua analista: “A senhora está notando alguma coisa?". Visivelmente decepcionada por a analista não conseguir notar o que ela desejava que fosse percebido, a paciente arregaça as mangas da blusa e exibe o pulso até então coberto, dizendo: "perdi o meu relógio". Esta fala pode servir como exemplo para ilustrar a sensação de transparência e a "externalidade" subjetiva que perpassa tais organizações, balizadas mais pelo sentimento de obviedade dos entes e de si do que pelo mistério interiorizado e pela confabulação imaginativa.

Ao mesmo tempo, foi observado um sentimento de estranheza com relação às sensações e percepções do próprio corpo, e até mesmo, em alguns casos, uma negação da realidade objetiva desse corpo. Neste sentido, verificamos também a alteração na capacidade de nomeação das sensações corporais. Certa vez, uma das pacientes narrou um episódio em que fora a um dentista para tratar de uma dor de dente. $\mathrm{O}$ profissional percebeu que seu problema e sua dor em nada se relacionavam com questões odontológicas e, após uma breve conversa, constatou que o problema poderia ser gástrico e imediatamente fez o encaminhamento para um clínico do mesmo hospital, que por sua vez diagnosticou uma úlcera já bastante avançada. A paciente foi para a emergência no mesmo dia, "com dores muito fortes de estômago". Ao ser questionada se sentira tal dor de estômago antes desse episódio - já que sua queixa era de "dor de dente" -, respondeu: "eu devia sentir a dor antes". Somente a partir do discurso médico pôde localizar e nomear a sua dor, antes difusa. Esta vinheta clínica permite ilustrar a precariedade do mapeamento corporal desta paciente: foi necessário que um outro lhe dissesse o quê e onde sentia para que ela pudesse efetivamente sentir a própria dor, a dor do 
seu próprio corpo. Sua idéia de unidade corporal é atravessada necessariamente pela fala de um outro, já que o que ela mesma vê ou sente não é suficiente para lhe conferir uma certeza de si. Aquilo que acontece com o corpo e, conseqüentemente, consigo própria tem que passar constantemente pelo crivo e pelo assentimento de um outro que o nomeia. Sem um estofo interno solidamente ancorado, essas pacientes tornam-se "reféns" de um discurso externo, muitas vezes o único capaz de lhes conceder atributos de existência que as organize minimamente. Aquilo que se é ou que o espelho mostra - como no exemplo do tratamento dos tiques narrado por Ferenczi - passa a ser o que outro diz. É a esta questão que procuraremos dar seguimento agora.

\section{O OLHAR E A FUNÇÃo ATRIBUTIVA}

Lambotte (1997) circunscreve essa modalidade subjetiva em sua metapsicologia da melancolia, ao propor a noção de moldura vazia. Sua hipótese é a de que, no encontro da mãe com seu bebê, o olhar materno o atravessou sem nele se fixar, ultrapassando-o para se depositar em um ponto para além dele. Podemos considerar que nessa operação há a constituição de uma moldura, ou seja, que o olhar lançado pela mãe atesta a existência do corpo do bebê, porém este não se torna alvo da intencionalidade dessa mãe. Recorrendo à metáfora da autora, resta, portanto, uma moldura vazia de atributos, destituída de desejo. Este seria o "acidente" narcísico que marcaria a constituição da subjetividade melancólica. Diante disso, o sujeito precisaria recorrer permanentemente ao olhar de um outro para que tivesse a garantia da continuidade de sua existência, não sem, para isso, implicar a sua corporeidade, último reduto possível para algum tipo de organização e sustentação de si.

Se esse corpo não foi alvo de um investimento desejante de um outro, ele resta como um corpo que apenas existe, privado de atribuições. Em nossas pacientes, resta um corpo que dói e que opera como prova concreta da existência. No caso das pacientes lúpicas, o corpo é o palco onde se mostram por meio da doença auto-imune que as acomete. Em função da doença somática que possuem, elas são submetidas a um rigoroso acompanhamento médico, de modo que falar de si passa a ser falar da história de sua doença.

Neste sentido, consideramos que o discurso médico atua como uma função atributiva (Herzog e Pinheiro, 2003); é organizador da imagem corporal, além de possibilitar a construção de uma identidade. $\mathrm{O}$ discurso médico sobre o corpo doente funciona nesses casos como a apropriação de um vocabulário por meio do qual essas pacientes podem falar de si. À medida que o corpo é tocado, delimita- 
do, cuidado, visto e falado por um outro que dele sabe, a doença pode se constituir como uma possibilidade identificatória para essas pessoas. $\mathrm{O}$ corpo doente ganha o interesse por parte dos médicos, ou seja, é alvo de um olhar intencionado que, além de atestar a sua existência, constrói uma narrativa sobre ele, proporcionando-lhe atributos.

Nesse contexto, os sujeitos constroem uma narrativa sobre si a partir dos seus diagnósticos e prontuários, como uma possibilidade de registro e inscrição da própria história. É uma forma de estabilizar minimamente a imagem corporal precária e evanescente. No momento em que a fala médica se dirige para o corpo, esses pacientes podem adquirir um "saber" sobre o próprio corpo e, então, construir um eixo identificatório em torno do qual passam a se organizar narcisicamente.

É significativo o modo como uma das pacientes lúpicas se apresenta à sua analista: "tenho síndrome de Raynaud. O lúpus é interrogado; vi escrito na ficha no Fundão". A identificação da paciente gravitava em torno dessas duas hipóteses diagnósticas, a ponto de ter levado à analista todos os seus prontuários, exames, etc.

É comum entre as pacientes da pesquisa uma grande atenção à denominação médica das patologias, que passam a lhes conferir seus próprios nomes e sobrenomes. É o caso também de uma outra paciente que, além do Lúpus, afirma ter Síndrome de Sjögren, à qual se refere de modo bastante enfático e recorrente, apesar de não ter esse diagnóstico médico confirmado. Queixa-se dos sintomas desta síndrome e carrega consigo todo o material de apoio para os pacientes portadores de Sjögren. Atualmente, a paciente freqüenta o grupo de pacientes lúpicos no HUCFF e descobriu que existe um "grupo de tabagistas" no mesmo hospital. Logo pediu para freqüentar também esse grupo, pois quer parar de fumar. Ela diz: "acho bonito ter uma tribo". O diagnóstico de Lúpus é adotado aqui como uma tribo, um nome, acrescido ainda de um "sobrenome", a síndrome de Sjögren.

Pensamos que nesses casos a construção do corpo como algo próprio é um processo inacabado, ainda por se fazer, dependente da idéia de ser doente e dos nomes que recebe. $\mathrm{O}$ fato de esses sujeitos contarem suas histórias a partir do desencadeamento da doença - estabelecendo uma cronologia a partir de diagnósticos, procedimentos médicos e da regularidade com que freqüentam ambulatórios e enfermaria - confere a eles uma ancoragem capaz de organizar um texto sobre o próprio corpo e, conseqüentemente, sobre si.

Outra decorrência dessa filiação ao discurso médico é que os hospitais de referência dessas pacientes (HUCFF e IPUB) acabam por funcionar como laço social em que, com a familiarização com as rotinas do serviço, passam a possibilitar uma noção de pertencimento.

Ao contrário, nas pacientes melancólicas não portadoras de Lúpus, o discurso psiquiátrico não parece ser capaz de proporcionar essa função atributiva, talvez 
porque justamente não se dirija de modo tão direto para o corpo. O mesmo ocorre, por exemplo, com os pacientes deprimidos. Estes têm muito mais dificuldade em mapear e sentir o corpo. Acreditamos que isto se dê por eles não contarem com os predicados médicos que auxiliam no mapeamento corporal. $\mathrm{O}$ diagnóstico psiquiátrico de depressão que o melancólico recebe não possui a mesma função organizadora que se sustenta no caso das lúpicas. $\mathrm{O}$ discurso médico confere a possibilidade de uma fala sobre si de que o melancólico não dispõe. A fala do corpo mediada pelos prontuários dá às melancólicas lúpicas um recurso subjetivo diferenciado, do qual elas vão se apropriar. Um exemplo ilustrativo disto é o caso, que já mencionamos anteriormente, da paciente melancólica que confundiu dor de estômago com dor de dente. A partir do momento em que ela se vê nas mãos de um médico e que este diagnostica uma úlcera, assistimos a uma significativa ordenação subjetiva dessa paciente. Pelo acompanhamento do caso, notamos que esse episódio exerceu importantes efeitos sobre a estabilidade de sua imagem corporal, tão dependente de diagnósticos.

Sendo assim, nas conformações subjetivas de que tratamos aqui, o corpo está sempre sendo convocado a provar a sua própria existência quer seja nas relações que essas pessoas estabelecem consigo mesmas, quer seja nas que estabelecem com o outro. Nesse sentido, portanto, o corpo está aquém daquilo que em psicanálise definimos como corpo erógeno. $\mathrm{Na}$ condição de não constituído pelo investimento desejante do outro, o corpo do melancólico subsiste apenas concretamente. Ele não remete ao referencial prazer/desprazer característico do corpo histérico que Freud tão bem nos descreveu, nem mesmo ao corpo sexual, paradigma do estatuto de corpo em psicanálise.

Ao contrário, encontramos nas pacientes da pesquisa uma narrativa desprovida de afeto sobre sexualidade e um desinteresse pela atividade sexual. De uma maneira mais ampla, apresentam até mesmo uma rejeição a contatos corporais de natureza terna, como abraços e carinhos. Por outro lado, o toque nesse corpo é bem-vindo em função dos cuidados e procedimentos médicos ou terapêuticos, como exames, cirurgias, etc. Esse corpo, portanto, não parece ser um corpo do prazer, mas um corpo da necessidade.

Pensamos ser essa a especificidade com que o corpo comparece em uma conformação subjetiva que se constituiu na ausência da marca de uma projeção e invenção narcísica. Freud (1914/1996), em Sobre o narcisismo: uma introdução, postula que a constituição da subjetividade é tributária de uma projeção do narcisismo dos pais na criança, ou seja, é produto de uma idealização. Nessa construção freudiana, o eu narcísico e, conseqüentemente, a unificação da imagem de si 
nascem da ficção montada na fantasia de dois adultos (Pinheiro, 2002). Nos casos aqui tratados, a configuração psíquica parece remontar a uma outra cena, em que a invenção subjetiva não foi fruto de um investimento desejante do outro e, assim, não se constituiu na onipotência da "Sua majestade o bebê". Nesse contexto, a assunção e apropriação de uma imagem fica prejudicada diante da ausência de um olhar capaz de lhe fornecer atributos. O corpo parece restar como o único território possível para atestar a existência do sujeito, veículo privilegiado na construção de sua identidade - só que agora não mais como alvo de um olhar de júbilo, mas como palco de um sofrimento corporal por meio do qual ele vai buscar para si a atenção e o reconhecimento constante do outro.

Mais do que um corpo erotizado, pleno de sentidos, que se oferece à interpretação, observamos nesses casos um corpo que se oferece ao cuidado. Segundo Costa $(2005)^{4}$, nesse tipo de pacientes o medo de morrer é inferior ao medo de perder o sentido da vida, de não saber o que fazer com ela. Enquanto eles estão sendo cuidados, suas vidas têm um sentido.

\section{Conclusão}

Nossa observação aponta para algumas conclusões. No caso das lúpicas, ocorre geralmente uma comunicação médica quanto à incurabilidade da doença, no momento do diagnóstico. Não sabemos se em decorrência disso, ou por um prejuízo da ilusão, não verificamos nessas pacientes nem o anseio pela cura, nem angústia pela incurabilidade - fato contrastante com o observado nas pacientes não lúpicas, que aspiram à remissão de seu quadro. Entretanto, o ideal do cuidado é encontrado tanto em pacientes melancólicas lúpicas quanto nas melancólicas não lúpicas. Ferenczi (1933/1992), nos seus textos sobre a teoria do trauma, fala da função de cuidado que esses pacientes ocupam junto aos mais próximos, tendo algumas vezes um lugar de assistente psiquiátrico e demonstrando sempre uma posição altruísta ou de extrema generosidade. Uma das pacientes lúpicas lamentou durante várias semanas o fato de ter sido informada de que não poderia doar um rim para alguém que precisasse.

Uma outra característica em torno desta questão do cuidado, comum a todas as pacientes, é uma mobilização, em algum momento de suas respectivas histórias, em volta de uma outra pessoa que necessita de cuidados corporais de diversas ordens. Um dado significativo dessa posição subjetiva é a constância com que essas pacientes escolhem a profissão de auxiliar de enfermagem. 
Apesar da rotina exaustiva que os cuidados dispensados ao outro exigem, não observamos uma postura de vitimização, o que aponta para uma grande diferença entre essas pacientes e aquelas com quadro de histeria. Ao contrário, verificamos um eixo identificatório montado em cima da obstinação, da coragem e da lucidez, emblemas pelos quais elas querem ser reconhecidas.

É, então, no exercício de cuidar e ser cuidado que essas pacientes encontram uma forma de dar contorno a seu próprio corpo, adquirindo aí os limites de uma idéia mínima de unidade corporal, bem como o estofo necessário para criar a sua própria ficção. O discurso e o cuidado médicos sobre o corpo parecem ter o estatuto de investir esses sujeitos, participando ativamente de um processo de construção de uma narrativa perpassada pelo narcisismo.

É assim que o prontuário e a fala médica, por si sós, são capazes de organizar minimamente a vida desses sujeitos. Contudo, a experiência clínica de acompanhamento dessas pacientes nos permite vislumbrar que o atendimento analítico pode propiciar uma apropriação subjetiva desse discurso.

Observamos que, durante o período de análise, não houve um agravamento das doenças auto-imunes. Isto nos sugere que o tratamento psicanalítico pode estar operando como um veículo de escoamento da angústia e de construção de novos meios de simbolização, de modo a ocupar o lugar outrora desviado para o corpo. Nossa aposta é de que a expansão do repertório simbólico propicie uma nova possibilidade de subjetivação que não a do adoecimento corporal.

\section{REFERÊNCIAS BIBLIOGRÁFICAS}

Araújo, G. R.B. (1989). De "lupus" et homine: contribuição a uma definição do espaço de atuação do psiquiatra em hospital geral. Dissertação de Mestrado, IPUB-UFRJ. - (2000). Correlatos psiquiátricos e neuropsicológicos no lúpus eritematoso sistêmico: comparação com a atrite reumatóide e a miastenia gravis. Tese de Doutorado, IPUBUFRJ.

Ferenczi, S. (1921). Reflexões psicanalíticas sobre os tiques. Em Psicanálise III. São Paulo: Martins Fontes, 1988.

. (1933). Confusão de línguas entre os adultos e a criança. Em Psicanálise IV. São Paulo: Martins Fontes, 1992.

Freud, S. (1914). Sobre o narcisismo: uma introdução. Em Obras completas (vol. XIV). Rio de Janeiro: Imago, 1996. 
Herzog, R. e Pinheiro, T. Impasses na clínica psicanalítica: a invenção da subjetividade. Disponível em: www.estadosgerais.org/mundial_rj. Acesso em 2003.

Lambotte, M. C. (1997). O discurso melancólico: da fenomenologia à metapsicologia. Rio de Janeiro: Companhia de Freud.

Pinheiro, T. e Verztman, J. (2003). As novas subjetividades, a melancolia e as doenças auto-imunes. Em Pinheiro, T. (Org.). Psicanálise e formas de subjetivação contemporâneas. Rio de Janeiro: Contra Capa.

Pinheiro, T. (1998a). O estatuto do objeto na melancolia. Em Kishida, C. A. et al. Cultura da Ilusão (pp. 119-130). Rio de Janeiro: Contra Capa.

. (1998b). A questão do superego na melancolia. Boletim de Novidades Pulsional, 108, 27-35.

. (1999). Em busca de uma metapsicologia da melancolia. Em Birman, J. (Org.). Sobre a psicose (pp. 29-44). Rio de Janeiro: Contra Capa.

. (2002). Escuta psicanalítica e novas demandas clínicas: sobre a melancolia na contemporaneidade. Em Psychê, ano VI, 9, 167-176. São Paulo.

Verztman, L e De Paola, D. (1981). Colagenoses - doenças difusas do tecido conjuntivo. Rio de Janeiro: Epume.

Verztman, J.; Pinheiro, T. e Montes, F. (2004). Doença somática e subjetividade: as marcas no corpo de Aurora. Pulsional Revista de Psicanálise, ano XVII, 179, setembro/2004, 54-65.

\section{Notas}

1 Essa pesquisa é resultado do acordo entre o programa de Pós-graduação em Teoria Psicanalítica da UFRJ, Instituto de Psiquiatria da UFRJ e o setor de saúde mental do ambulatório de colagenoses do Hospital Universitário Clementino Fraga Filho. Os coordenadores são Professora Teresa Pinheiro (do PPG em Teoria Psicanalítica) e Dr. Julio Verztman - IPUB). Gostaríamos de destacar a participação indispensável da Dra. Glória Araújo - psiquiatra do ambulatório de colagenoses do HUCFF -, responsível pelo encaminhamento das pacientes lúpicas, além de participar das reunióes de pesquisa e dos eventos promovidos pela pesquisa.

2 O termo Lúpus foi usado para descrever condições cutâneas mórbidas há pelo menos sete séculos, mas Kaposi faz referência ao herpes esthiomenos de Hipócrates (430 a 370 a.C.) e o Herpes ulcerosus de Augustus Susitamis (1510 a 1560). O Lúpus Eritematoso Sistêmico descrito pela primeira vez por Biett, em 1833, é uma afecção freqüente que aparece em 30 a 40 casos para cada 
100.000 habitantes, sendo mais freqüente em mulheres, na proporção de $7 / 1 \mathrm{e}$ atingindo sobretudo as idades entre os 20 e os 40 anos. O LES (Lúpus Eritematoso Sistêmico) é uma doença do tecido conjuntivo, auto-imune, com manifestações predominantemente cutâneas, cardiovasculares, renais, nervosas e articulares, dentre outras, mas que pode comprometer praticamente todo o organismo e levar à morte (ver Verztman e De Paola, 1981; Araújo, 1989, 2000). Numa determinada fase da vida, o organismo passa a não reconhecer suas próprias proteínas e as destrói através do seu sistema imunológico.

3 Para uma melhor elucidação das propostas da pesquisa, ver Pinheiro, T. e Verztman, J. (2003); Verztman, Pinheiro e Montes (2004) Pinheiro (1998a; $1998 \mathrm{~b} ; 2002)$. As considerações presentes neste artigo tiveram como ponto de partida algumas perguntas por nós formuladas sobre cada um dos casos atendidos, no que tange à dimensão corporal. São elas: há uma idéia mínima de unidade corporal? $\mathrm{O}$ sujeito reconhece o corpo como lhe pertencendo? Quais são as denominações singulares que apareceram nas sessões para as partes do corpo? Qual é a valorização singular para cada parte do corpo referida? A ocorrência de doença somática produz mais estabilidade para a imagem corporal? A denominação médica de uma doença produz mais estabilidade para a imagem corporal? Há vivências de ameaça de desintegração corporal? O corpo confere noção de divisão entre espaço interior e espaço exterior?

4 Comentário de Jurandir Freire Costa durante a apresentação de trabalho no III Encontro de Itatiaia, 2005.

Recebido em 26 de fevereiro de 2006 Aceito para publicação em 16 de março de 2006 